\title{
PROPIEDADES FÍSICAS, HIDRÁULICAS Y MECÁNICAS DE SUELOS DE ORIGEN VOLCÁNICO, EN SITIOS SELECCIONADOS DEL VALLE CENTRAL, COSTA RICA
}

\author{
Rolando Mora Ch. \\ Escuela Centroamericana de Geología, Apdo. 35-2060 Universidad de Costa Rica, \\ Correo electrónico: rolandom@ cariari.ucr.ac.cr
}

(Recibido 10/9/1998; Aceptado 16/11/1998)

\begin{abstract}
RESUMEN: Se han escogido cuatro sitios del Valle Central de Costa Rica, donde se ha realizado el estudio de los suelos de origen volcánico desde el punto de vista geotécnico. Se han medido las propiedades físicas, hidráulicas y de resistencia al corte de los materiales, con la incorporación de una gran cantidad de trabajos de investigación realizados en la misma región, para así establecer sus rangos de variación y las posibilidades de utilización de los suelos volcánicos como sitios para la disposición final de desechos sólidos. Los suelos también se han estudiado con la ayuda del microscopio electrónico de barrido, con la idea de interpretar su comportamiento macroscópico desde una perspectiva microscópica.
\end{abstract}

\begin{abstract}
Four localities in Valle Central de Costa Rica have been selected to study the volcanic soils from a geotechnical point of view. The materials have been tested, measuring their physical, hidraulic and shear resistance properties, also incorporating results from other research works, trying to delimit their ranges of variation and the possibilities to use them as final places for deposition of solid waste. The soils have been studied with the help of the scanning elektron microscope, in order to interpret their macroscopic behavior by an microscopic approach.
\end{abstract}

\section{INTRODUCCIÓN}

La cuantificación de las propiedades físicas, mecánicas e hidraúlicas de los materiales de origen volcánico, es una labor poco difundida a través de las publicaciones técnicas y científicas de nuestro país. Los esfuerzos han sido dirigidos a brindar soluciones para proyectos específicos, y los datos han sido consignados en informes internos de las diferentes instituciones, o en informes de carácter privado (empresas privadas). De esta manera, la información muchas veces se torna inaccesible. Este trabajo pretende difundir los resultados de varios ensayos de campo y laboratorio, ejecutados en sitios seleccionados del Valle Central, los cuales se han realizado con el fin de comprender mejor el comportamiento de los suelos de origen volcánico.

Se han escogido cuatro lugares con depósitos volcánicos de edades y litologías bastante diferentes entre sí. El sitio denominado Finca Ivancovich se localiza en el cantón de Oreamuno, provincia de Cartago, en las coordenadas 206200N y 549700E (Fig. 1a). El área se encuentra dentro del Miembro Superior de la Formación Reventado, el cual está compuesto por coladas de lava andesítica augítica, lahares y capas de ceniza, tiene un espesor probable de 600 $\mathrm{m}$ y su edad radiogénica es de 147.000 años (Krushensky, 1972). Propiamente en el lugar, se observa una capa de cenizas de 4,40 m de espesor, la que es subyacida por un lahar de 3,20 m, 
este a su vez es subyacido por una colada de lava meteorizada, de la que se observa un espesor de $3,40 \mathrm{~m}$.

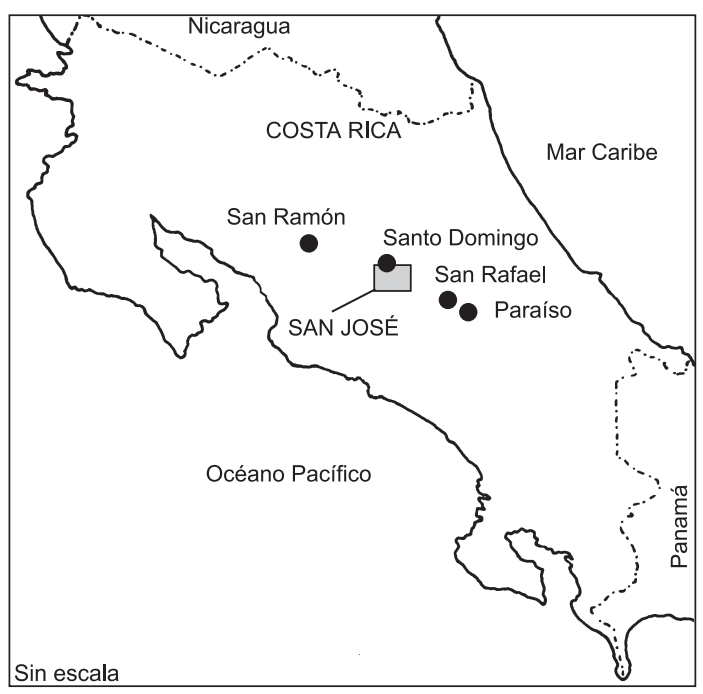

Fig. 1: Localización de los sitios seleccionados.

El sitio denominado Río Títere se localiza en el cantón de Paraíso, provincia de Cartago, en las coordenadas $203750 \mathrm{~N}$ y $555000 \mathrm{E}$ (Fig. 1b). Este lugar se encuentra dentro del Miembro Cama de Ceniza de la Formación Reventado, el cual está compuesto de cenizas de color rojo, de grano fino y profundamente meteorizadas (Krushensky, 1972). Las cenizas finas, muy meteorizadas se encuentran hasta profundidades de 3,2 m, también se observan coladas de lava, muy meteorizadas, a profundidades variables, y bloques sanos de lavas andesíticas en las partes superiores del perfil de suelos.

El sitio Santo Domingo se localiza entre las coordenadas $216000-217000 \mathrm{~N}$ y 526000 527000E, (Fig. 1c), en el lugar afloran tobas de la Formación Tiribí (Echandi, 1981), con un espesor aproximado de $30 \mathrm{~m}$. Denyer \& Arias (1991) incluyen estos depósitos de caída dentro de la Formación Depósitos de Avalancha Ardiente. Subyaciendo estos materiales se encuentran las lavas densas y brechosas del Miembro La Libertad, descritas por Echandi (1981) como miembro
Linda Vista de la Formación Colima, con un espesor aproximado de $90 \mathrm{~m}$ y que dan origen al acuífero La Libertad. Luego aparece un espesor aproximado de $15 \mathrm{~m}$ de tobas arcillosas y subyaciendo estos depósitos se encuentran las lavas del Miembro Colima Superior de la Formación Colima (Echandi, 1981), las cuales a su vez dan origen al acuífero Colima Superior.

El sitio Bolívar se localiza entre las coordenadas $232000-233000 \mathrm{~N}$ y 483000 - 484000E, (Fig. 1d), geológicamente se correlaciona con la Unidad Piroclástica de Caída del Pleistoceno Superior (Alvarado, 1994) y que esta constituida por tobas de caída poco consolidadas y alteradas intensamente. Alvarado (1994) considera un espesor mínimo para la unidad de $50 \mathrm{~m}$, ya que el espesor real se desconoce.

\section{PROPIEDADES FÍSICAS}

Todos los depósitos de los sitios seleccionados presentan un estado avanzado de meteorización; sus propiedades físicas principales se aprecian en el cuadro 1. En la figura 2 se observan los rangos de variación de algunas de las propiedades fisicas de los depósitos de origen volcánico del Valle Central, tomando en consideración las mediciones realizadas por varios autores. Las diferentes litologías presentan rangos amplios de variación en todas sus propiedades, posiblemente a causa de diversos estados de meteorización en que se encuentran, así como a las variaciones mineralógicas. Se torna prácticamente imposible discriminar los diversos productos volcánicos de acuerdo con estas propiedades, por lo tanto, para proyectos específicos se hace necesaria la ejecución de ensayos de campo y laboratorio para su determinación.

Es importante hacer notar los valores altos de la porosidad de los materiales volcánicos. Esto no significa una conductividad hidráulica alta, pues los vacíos no siempre se encuentran interconectados, o se da en ellos el desarrollo de minerales arcillosos secundarios por meteorización. 
Cuadro 1

Propiedades físicas principales

\begin{tabular}{llccccccc}
\hline Muestra & Litología & $\begin{array}{c}\text { Gravedad } \\
\text { específica }\end{array}$ & $\begin{array}{r}\text { Peso unitario } \\
\text { húmedo } \\
{\left[\mathrm{kN} / \mathrm{m}^{3}\right]}\end{array}$ & $\begin{array}{c}\text { Peso unitario } \\
\text { seco } \\
{\left[\mathrm{kN} / \mathrm{m}^{3}\right]}\end{array}$ & $\begin{array}{c}\text { Peso unitario } \\
\text { de } \begin{array}{c}\text { los sólidos } \\
{\left[\mathrm{kN} / \mathrm{m}^{3}\right]}\end{array}\end{array}$ & $\begin{array}{c}\text { Relación de } \\
\text { vacíos }\end{array}$ & $\begin{array}{c}\text { Porosidad } \\
{[\%]}\end{array}$ & $\begin{array}{c}\text { Grado de } \\
\text { saturación } \\
{[\%]}\end{array}$ \\
\hline $\mathrm{FI} / 1$ & cenizas & 2,69 & 15,0 & 9,8 & 26,4 & 1,7 & 63 & 85 \\
$\mathrm{FI} / 2$ & lahar & 2,68 & 15,6 & 10,1 & 26,3 & 1,6 & 62 & 90 \\
$\mathrm{FI} / 3$ & lavas & 2,65 & 14,1 & 9,7 & 26,0 & 1,7 & 63 & 72 \\
$\mathrm{RT} / 1$ & cenizas & 2,70 & 17,3 & 12,8 & 26,5 & 1,1 & 52 & 88 \\
$\mathrm{RT} / 2$ & cenizas & 2,68 & 17,0 & 12, & 26,3 & 1,1 & 52 & 88 \\
$\mathrm{RT} / 3$ & cenizas & 2,68 & 16,3 & 11,5 & 26,3 & 1,9 & 65 & 83 \\
$\mathrm{RT} / 4$ & lavas & 2,68 & 16,8 & 11,5 & 26,3 & 1,3 & 56 & 96 \\
$\mathrm{SD} / 1$ & tobas & 2,69 & 16,5 & 11,8 & 26,4 & 1,2 & 55 & 86 \\
$\mathrm{SD} / 2$ & tobas & 2,69 & 16,4 & 11,7 & 26,4 & 1,3 & 56 & 86 \\
$\mathrm{SB} / 1$ & tobas & 2,69 & 15,5 & 10,1 & 26,4 & 1,6 & 62 & 88 \\
$\mathrm{SB} / 2$ & tobas & 2,69 & 15,8 & 10,4 & 26,4 & 1,5 & 61 & 92 \\
\hline
\end{tabular}

\section{Límites de consistencia}

La determinación del límite líquido y límite plástico se ha realizado siguiendo las normas de la ASTM (1993). Los resultados para los sitios seleccionados aparecen en el cuadro 2 y la figura 3a. En la figura 3b, se muestran los resultados obtenidos en suelos volcánicos por otros autores (Protti, 1993; Chaves \& Avilés, 1993; Bonilla, De Lemos \& Fallas, 1993; Macías \& Zamora, 1993; Tristán, 1994; Fajardo, 1994; Villegas, 1994; Arias, 1995; Alpízar, 1995; Brenes, 1995; Vargas, 1995; Salazar, 1995; Mora, 1995), además de otros trabajos realizados por la Empresa Auxiliar 04 de la Escuela Centroamericana de Geología.

En ambos gráficos se observa que los productos de la meteorización de materiales volcánicos se agrupan, principalmente, en el rango que corresponde con los limos de plasticidad alta $(\mathrm{MH})$, con cierta tendencia hacia los limos de plasticidad muy alta (MV), posiblemente debido al estado más avanzado de meteorización que presentan.

Nagaray \& Jayadeva (1981) han propuesto una ecuación para la determinación del límite líquido con un único punto, utilizando el aparato de Casagrande:

$w L=w / 1-K(\log N-\log 25)$,

donde: wL es el límite líquido, w el contenido de humedad correspondiente a un punto de $\mathrm{N}$ golpes, $\mathrm{y}$

$\mathrm{K}$ es el valor numérico de la pendiente de la linea representada por w/wL contra $\log \mathrm{N}$.

Los mismos autores proponen la ecuación para la determinación del límite líquido, con el método de un único punto, como:

$$
\mathrm{wL}=\mathrm{w} /(1.3215-0.23 * \log \mathrm{N})
$$

Cuadro 2

Límites de consistencia

\begin{tabular}{llllll}
\hline Muestra & Litología & $\begin{array}{c}\text { Límite } \\
\text { líquido \% }\end{array}$ & $\begin{array}{c}\text { Límite } \\
\text { plástico } \%\end{array}$ & $\begin{array}{c}\text { Índice de } \\
\text { plasticidad }\end{array}$ & Clasificación \\
\hline FI/1 & cenizas & 56,5 & 36,7 & 19,8 & $\mathrm{MH}$ \\
$\mathrm{FI} / 2$ & lahar & 57,0 & 39,5 & 17,5 & $\mathrm{MH}$ \\
$\mathrm{FI} / 3$ & lavas & 59,9 & 36,3 & 23,6 & $\mathrm{MH}$ \\
$\mathrm{RT} / 1$ & cenizas & 49,4 & 30,7 & 18,7 & $\mathrm{MI}$ \\
$\mathrm{RT} / 2$ & cenizas & 60,9 & 43,8 & 17,1 & $\mathrm{MH}$ \\
$\mathrm{RT} / 3$ & cenizas & 50,4 & 30,5 & 19,9 & $\mathrm{MH}$ \\
$\mathrm{RT} / 4$ & lavas & 51,3 & 32,1 & 19,2 & $\mathrm{MH}$ \\
$\mathrm{SD} / 1$ & tobas & 52,7 & 31,3 & 21,4 & $\mathrm{MH}$ \\
$\mathrm{SD} / 2$ & tobas & 50,7 & 32,8 & 17,9 & $\mathrm{MH}$ \\
$\mathrm{SB} / 1$ & tobas & 68,2 & 39,2 & 29,0 & $\mathrm{MH}$ \\
$\mathrm{SB} / 2$ & tobas & 70,8 & 44,3 & 26,5 & $\mathrm{MV}$ \\
$\mathrm{SB} / 3$ & tobas & 69,6 & 37,1 & 32,5 & $\mathrm{MH}$ \\
\hline
\end{tabular}

Con esta expresión, Nagaraj \& Jayadeva (1981), utilizando el rango de número de golpes entre 20 y 35 , han calculado que el error en la 

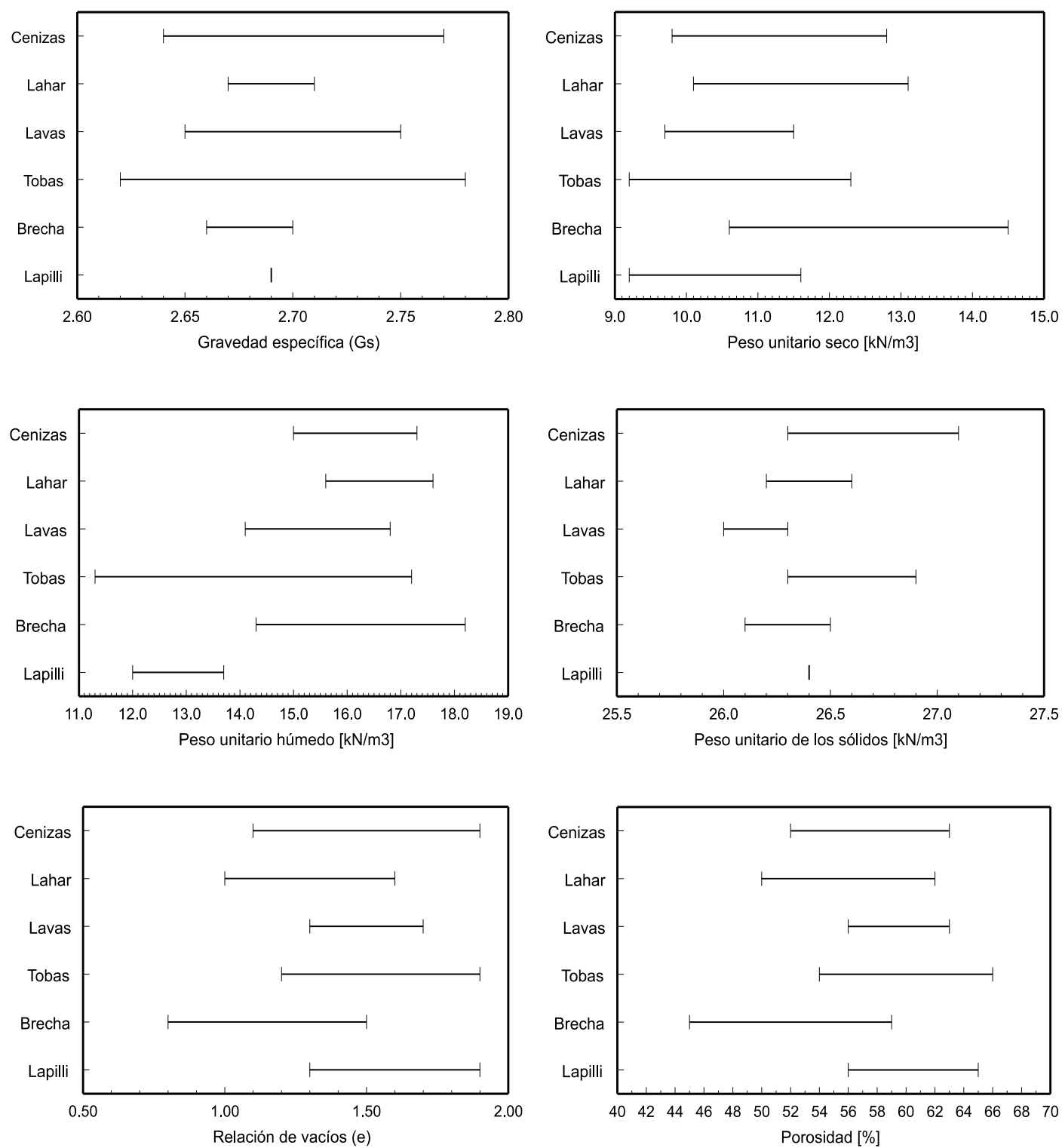

Fig. 2: Rangos de variación de algunas propiedades físicas de los depósitos meterizados de origen volcánico. 

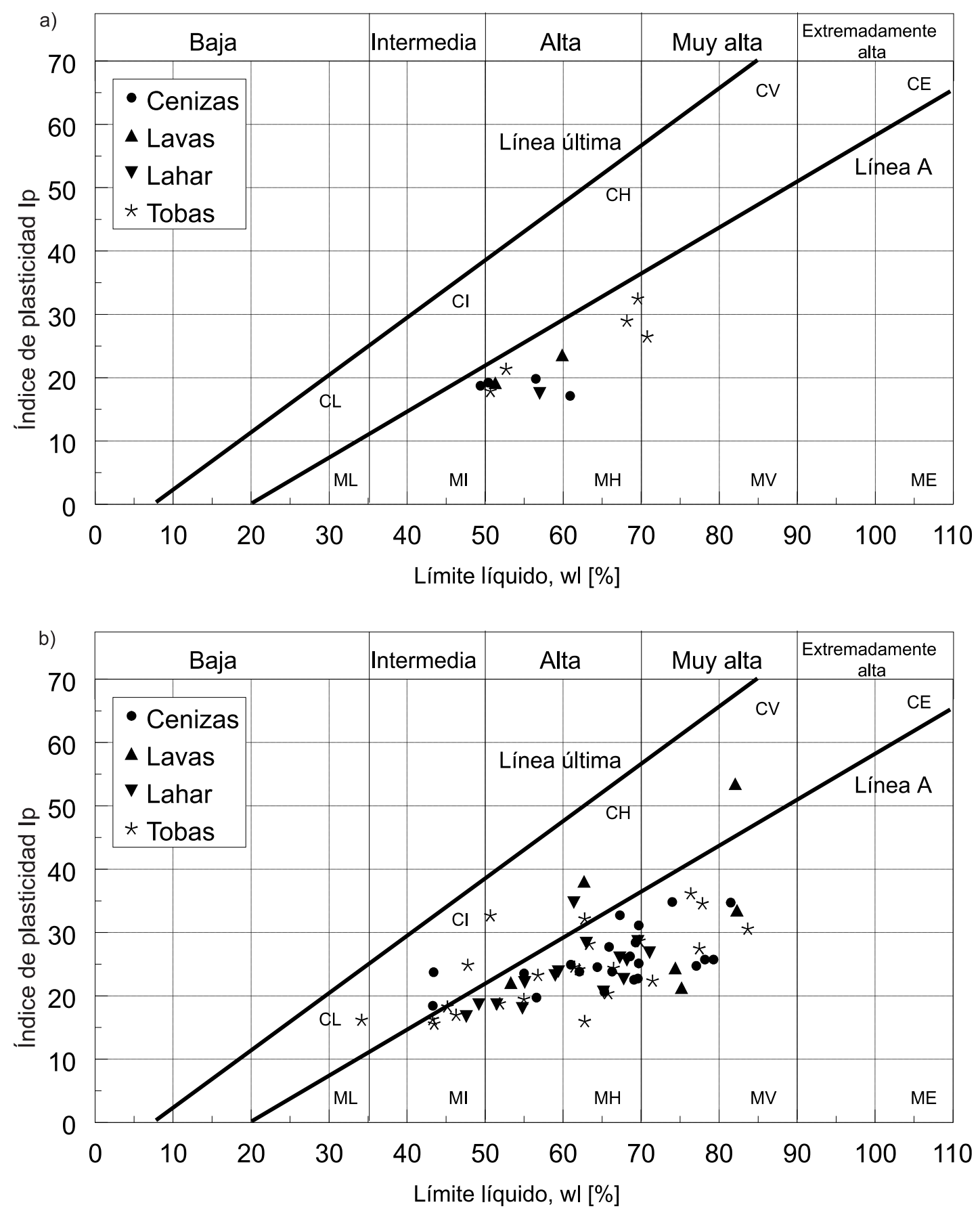

Fig. 3: Límites de consistencia de los productos de meteorización de los depósitos de origen volcánico. 
determinación de los valores del límite líquido es menor de $\pm 1 \%$. Utilizando esta relación con los materiales volcánicos de los sitios seleccionados, se obtienen errores que oscilan entre $-11,3 \%$ y $7,2 \%$. Lo anterior significa que la expresión no es adecuada para este tipo de materiales y por lo tanto no puede considerarse como de carácter universal.

Se han utilizado los resultados de las determinaciones del límite líquido en los cuatro sitios seleccionados, para establecer el valor de $\mathrm{K}$ (Fig. 4) y así desarrollar una relación empírica para los suelos volcánicos del Valle Central:

$\mathrm{wL}=2.22-0.873 \log \mathrm{N}$

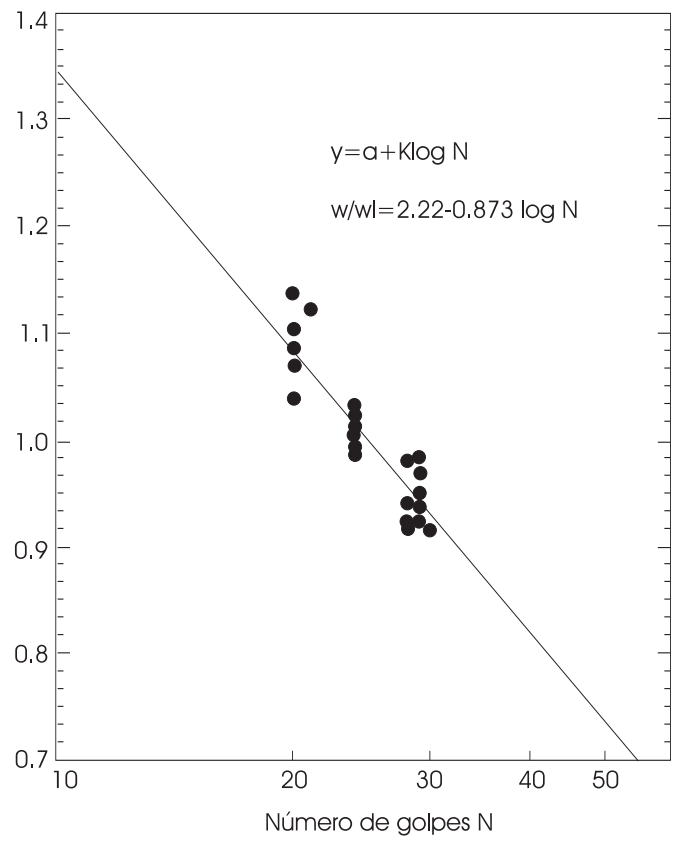

Fig. 4: Relación empírica para los suelos volcánicos.

En el desarrollo de esta ecuación se han empleado solamente los puntos donde el número de golpes oscila entre 20 y 30 . El error que se obtiene, para los mismos puntos que en el caso anterior, oscila entre $-5,4 \%$ y $4,1 \%$, lo cual la torna un poco más precisa que la ecuación anterior, pero sin cumplir plenamente con las expectativas.
A pesar de la base científica tan fuerte con que cuentan los métodos de un único punto, no se puede realizar una generalización para todo tipo de suelo. Se pueden establecer relaciones empíricas para suelos diversos, en regiones geográficas delimitadas, pero siempre se debe evaluar el error en que se puede incurrir con el uso de las mismas, y así juzgar su posibilidad de aceptación como método alternativo en proyectos de gran envergadura. Para proyectos que no involucren una enorme cantidad de muestras, se sugiere la determinación del límite líquido con el ensayo tradicional del aparato de Casagrande.

\section{Características granulométricas}

La determinación de las características granulométricas de los suelos de origen volcánico puede arrojar resultados dramáticamente diferentes, según el tipo de procedimiento que se utilice para establecer el porcentaje de peso de cada fracción y la clasificación del material. Una de las metodologías utiliza la disgregación de los componentes en un mortero de porcelana y el tamizado en seco, la otra emplea el agua como agente para pasar el material a través de los tamizes.

Muestras de los sitios seleccionados se ensayaron con ambas metodologías, los resultados se aprecian en la figura 5 y el cuadro 3. La clasificación de los materiales se modifica sustancialmente (de SM a MH), lo cual tiene implicaciones sumamente importantes desde el punto de vista de la utilidad de cada método, en el sentido de emplear el Sistema Unificado de Clasificación de Suelos (Bowles, 1982) como un lenguaje universal, con el cual se pueda tener una idea del comportamiento mecánico e hidráulico de cada suelo. Lo anterior se ha expresado en el sentido de que las propiedades mecánicas e hidráulicas de una arena limosa, son muy diferentes de las de un limo arenoso. La clasificación de la muestra FI/3 no se ha modificado, debido a que estas lavas no se encuentran en un estado de meteorización muy avanzado. 


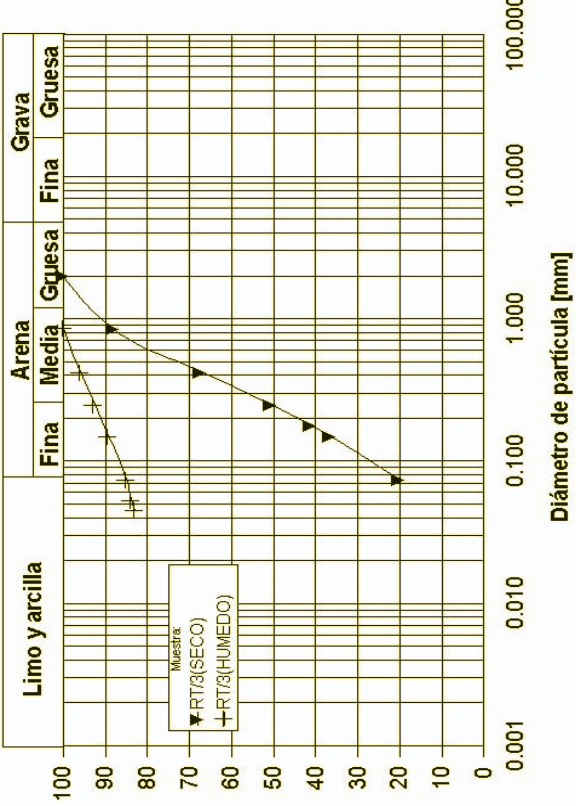

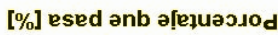
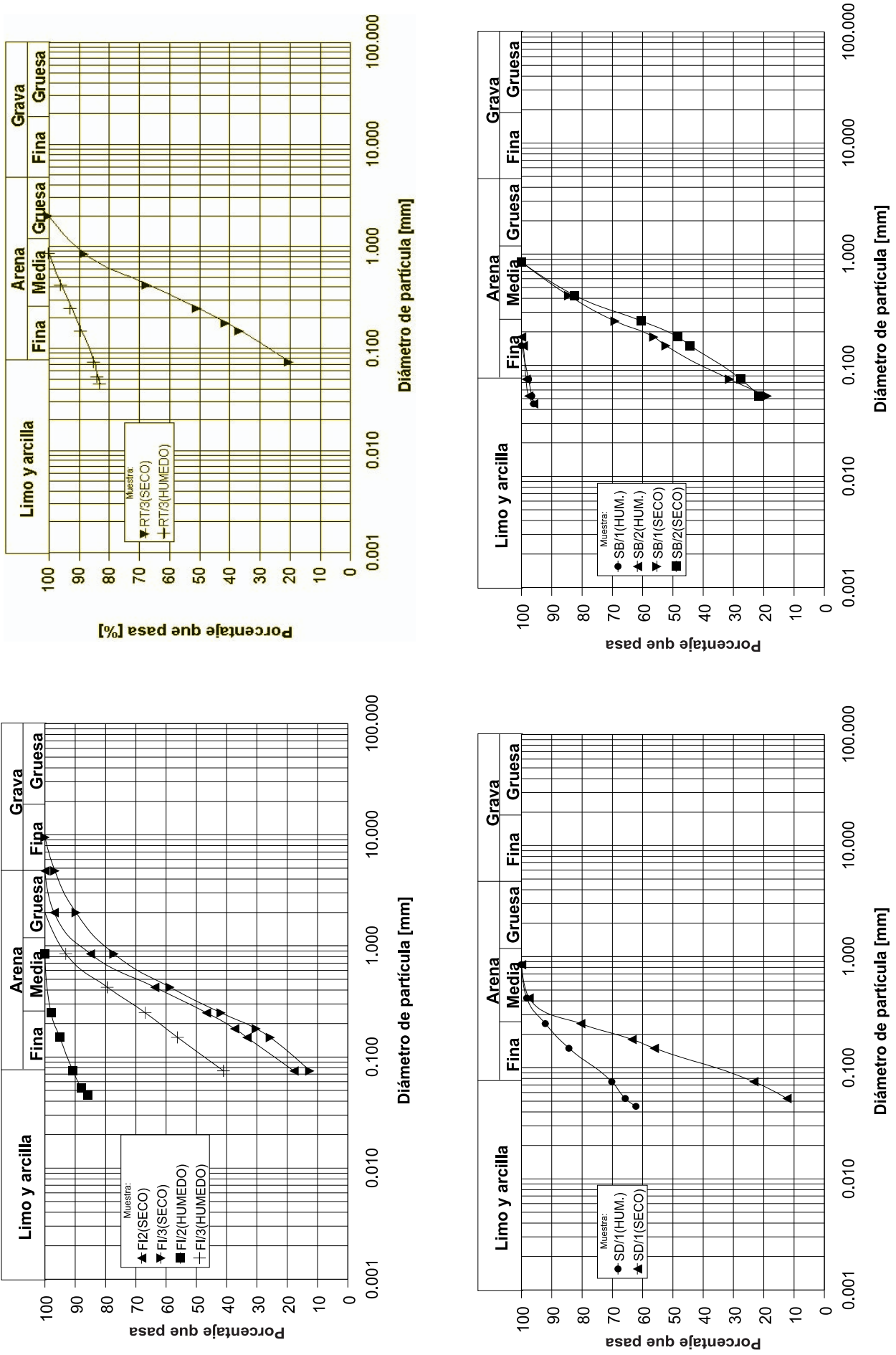

Fig. 5: Ensayos granulométricos. 
Cuadro 3

Características granulométricas de los suelos

\begin{tabular}{|c|c|c|c|c|c|c|c|c|c|c|c|c|}
\hline \multirow[t]{2}{*}{ Muestra } & \multirow[t]{2}{*}{ Litología } & \multirow{2}{*}{$\begin{array}{l}\% \text { grava } \\
\text { seco }\end{array}$} & \multirow[b]{2}{*}{ húm. } & \multicolumn{2}{|c|}{$\%$ arena gruesa } & \multicolumn{3}{|c|}{$\%$ arena media $\%$ arena fina } & \multicolumn{2}{|c|}{$\%$ finos } & \multicolumn{2}{|c|}{ Clasificación } \\
\hline & & & & seco & húm. & seco & húm. & seco & húm. & seco & húm & seco húm. \\
\hline $\mathrm{FI} / 2$ & lahar & - & - & 2.99 & - & 33.24 & - & 46.01 & 9.26 & 17.76 & 90.74 & SM MH \\
\hline $\mathrm{FI} / 3$ & lavas & 3,27 & - & 6,99 & - & 30,98 & 20.6 & 46,17 & 38.41 & 15,58 & 41.0 & SM SM \\
\hline $\mathrm{RT} / 3$ & cenizas & - & - & - & - & 32,63 & 4.06 & 47,15 & 10.99 & 20,22 & 84.95 & SM MH \\
\hline $\mathrm{SD} / 1$ & tobas & - & - & - & - & 2,52 & 1,75 & 74,19 & 28,08 & 23,29 & 70,18 & SM MH \\
\hline $\mathrm{SB} / 1$ & tobas & - & - & - & - & 15,58 & - & 53,14 & 1,48 & 31,28 & 98,52 & SM MH \\
\hline $\mathrm{SB} / 2$ & tobas & - & - & - & - & 17,58 & - & 54,88 & 2,34 & 27,54 & 97,66 & SM MV \\
\hline
\end{tabular}

Desde el punto de vista estructural podemos decir que estamos tratando con suelos cohesivos, los cuales son descritos por Bowles (1982) como un agregado de partículas minerales que tiene un índice de plasticidad definido por los límites de Atterberg y que forma una masa coherente al secarse, de manera que se requiere de un esfuerzo para separar los granos microscópicos individuales. Las fuerzas entre parículas tienen su origen en (Bowles, 1982): enlaces iónicos, enlaces de van der Waals, enlaces de hidrógeno y atracción gravitacional.

Con porcentajes de finos $(<0,074 \mathrm{~mm})$ como los expresados en el cuadro 3 (vía húmeda) para los suelos volcánicos estudiados, podemos esperar que las partículas mayores se encuentren suspendidas en una matriz de suelo fino y establecer que el ensayo vía seca no logra romper las fuerzas interparticulares, conservándose muchos de los agregados y originando resultados que no reflejan la realidad de la distribución granulométrica del depósito.

\section{CONDUCTIVIDAD HIDRÁULICA}

El equipo usado para medir la conductividad hidráulica saturada de campo es el permeámetro Guelph, modelo 2800KL. Este aparato opera basado en el principio del sifón de Mariotte y proporciona un método simple y rápido para determinar, simultáneamente, la conductividad hidráulica saturada de campo, el potencial de flujo de la matriz y la absorción del suelo (SEC, 1986).
La conductividad hidráulica es la medida de la capacidad de un suelo de conducir agua bajo un gradiente hidráulico unitario. La conductividad hidráulica saturada de campo (Kfs) se refiere a la conductividad hidráulica saturada de un suelo conteniendo aire atrapado (SEC, 1986). Para la zona vadosa (no saturada) Kfs es más apropiada que la conductividad hidráulica saturada real obtenida a partir de pruebas de bombeo, debido a que en situaciones no saturadas las condiciones de presión positiva no persisten el tiempo suficiente para disolver el aire atrapado (SEC, 1986).

Los resultados de las mediciones se aprecian en el cuadro 4. El rango de variación para los productos de la meteorización de materiales volcánicos es considerablemente amplio (1.0E-04 a $1.0 \mathrm{E}-07 \mathrm{~m} / \mathrm{s}$ ). Bowles (1982) establece que los suelos clasificados como SW, SP, SM y SC, cuentan con un coeficiente de permeabilidad que oscila entre 1.0E-04 y 5.0E-06. Como se pudo establecer anteriormente, los suelos volcánicos, ensayados con el método granulométrico vía seca, se clasifican como SM, esto quiere decir que la conductividad hidráulica de los mismos es gobernada por la macroestructura del conjunto de partículas.

\section{COMPACTACIÓN}

La compactación es la densificación de los suelos mediante la aplicación de energía mecánica (Bowles, 1982). En este estudio se han realizado los ensayos siguiendo las especificaciones de la ASTM (1993) para el ensayo de compactación Proctor Estándar. 
Cuadro 4

Resultados de las mediciones de conductividad hidráulica saturada de campo

$\begin{array}{lll}\text { Muestra } & \text { Litología } & \begin{array}{l}\text { Conductividad hidráulica } \\ \text { saturada de campo [m/s] }\end{array} \\ \text { FI/2 } & \text { lahar } & 2.1 \mathrm{E}-07 \\ \mathrm{FI} / 3 & \text { lavas } & 4.3 \mathrm{E}-07 \\ \mathrm{RT} / 2 & \text { cenizas } & 1.3 \mathrm{E}-07 \\ \mathrm{SD} / 2 & \text { tobas } & 3.3 \mathrm{E}-06 \\ \mathrm{SB} / 1 & \text { tobas } & 1.0 \mathrm{E}-04 \\ \mathrm{SB} / 2 & \text { tobas } & 1.5 \mathrm{E}-06\end{array}$

Los pesos unitarios secos de los suelos volcánicos analizados oscilan entre 9.8 y 13 $\mathrm{kN} / \mathrm{m} 3$, estos valores se pueden considerar muy bajos y se deben al gran volúmen de vacíos con que cuentan los suelos derivados de la meteorización de productos volcánicos (cuadro 1).

Los valores de los pesos unitarios secos máximos de las cenizas, en estado compactado, oscilan entre 11.5 y 13.6 kN/m3 (Fig. 6a). Los contenidos de humedad óptimos oscilan entre 30 y $43 \%$. El incremento en términos de peso unitario seco se ha expresado para cada muestra en el cuadro 5, siendo este en promedio de $11.9 \%$. El ámbito del rango presenta un comportamiento que se puede considerar como normal.

Para las lavas el intervalo de peso unitario seco máximo, en estado compactado, está entre 12.0 y $12.2 \mathrm{kN} / \mathrm{m} 3$, por su parte los contenidos de humedad óptimos varían entre 39 y $42 \%$ (Fig. $6 b)$, con un incremento promedio del $13.3 \%$ (cuadro 5); lo anterior indica un comportamiento muy consistente entre lavas meteorizadas provenientes de localidades diferentes.

Los materiales compactados también se han ensayado para medir su conductividad hidráulica, en su estado óptimo de compactación (cuadro 6), este proceso nos permite evaluar las posibilidades de utilizar los materiales volcánicos como sellos impermeables en el fondo de las trincheras, donde se depositen desechos sólidos..

Como se logra apreciar, la conductividad hidráulica se reduce, prácticamente, en dos órdenes de magnitud con el proceso de compactación, lo cual es sumamente satisfactorio pues se obtiene un material con características impermeables,
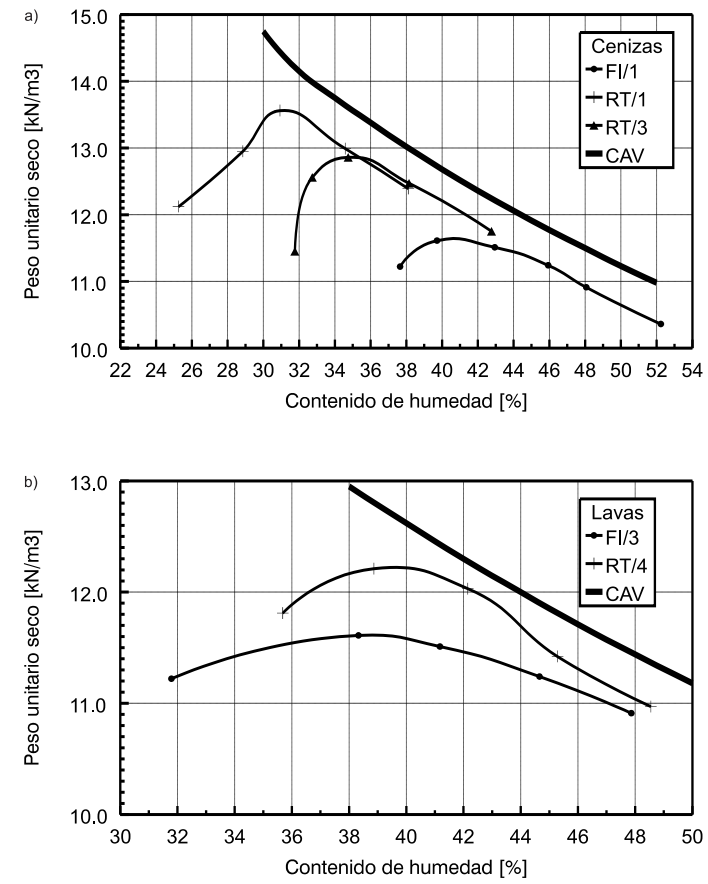

Fig. 6: Resultado de los ensayos de compactación.

el cual puede ser utilizado para el revestimiento de trincheras en rellenos sanitarios.

Es conveniente, en caso de que se desee utilizar el material en rellenos sanitarios, que se realize un control de la calidad de la compactación estricto, y que además se ejecuten ensayos de permeabilidad en el material compactado, para asegurarse de que se cumplan todas las especificaciones.

Cuadro 5

Cambios en el peso unitario seco por compactación en suelos volcánicos

\begin{tabular}{lllll} 
Muestra Litología Peso unitario & $\begin{array}{l}\text { Peso unitario } \\
\text { seco (natural) }\end{array}$ & $\begin{array}{l}\text { Incremento } \\
\text { seco máx. } \\
\text { (compactado) } \\
\text { porcentual }\end{array}$ \\
& & {$\left[\mathrm{kN} / \mathrm{m}^{3}\right]$} & {$\left[\mathrm{m}^{3}\right]$} & \\
\hline $\mathrm{FI} / 1$ & cenizas & 9.8 & 11.5 & 17.3 \\
$\mathrm{RT} / 1$ & cenizas & 12.8 & 13.6 & 6.3 \\
$\mathrm{RT} / 3$ & cenizas & 11.5 & 12.9 & 12.2 \\
$\mathrm{FI} / 3$ & lavas & 9.7 & 11.6 & 19.6 \\
$\mathrm{RT} / 4$ & lavas & 11.4 & 12.2 & 7.0 \\
\hline
\end{tabular}


Cuadro 6

Modificación de la conductividad hidráulica por compactación

\begin{tabular}{llll}
\hline Muestra & Litología & $\begin{array}{l}\text { Conductividad } \\
\text { hidráulica } \\
\text { original } \\
{[\mathrm{m} / \mathrm{s}]}\end{array}$ & $\begin{array}{l}\text { Conductividad } \\
\text { hidráulica } \\
\text { compactada } \\
{[\mathrm{m} / \mathrm{s}]}\end{array}$ \\
$\mathrm{FI} / 3$ & lavas & $4.3 \mathrm{E}-07$ & $6.2 \mathrm{E}-09$ \\
$\mathrm{SD} / 2$ & tobas & $3.3 \mathrm{E}-06$ & $1.6 \mathrm{E}-09$ \\
$\mathrm{SB} / 2$ & tobas & $1.5 \mathrm{E}-06$ & $3.6 \mathrm{E}-08$ \\
\hline
\end{tabular}

\section{PARÁMETROS DE RESISTENCIA AL CORTE}

Los parámetros efectivos de resistencia al corte se han evaluado mediante la realización de ensayos de corte directo consolidados-drenados (CD) (cuadro 7). Se observa que los productos de la meteorización de productos volcánicos cuentan con cohesiones efectivas muy bajas y con ángulos de fricción efectivos altos, con excepción de la muestra SB/3, la cual presenta un ángulo de fricción bajo.

\section{Cuadro 7}

Parámetros efectivos de resistencia al corte

$\begin{array}{llll}\text { Muestra } & \text { Litología } & \begin{array}{l}\text { Cohesión } \\ {[\mathrm{kPa}]}\end{array} & \begin{array}{l}\text { ángulo de fricción } \\ \text { interna [grados] }\end{array} \\ \text { FI/1 } & \text { Cenizas } & 4.9 & 32 \\ \mathrm{FI} / 2 & \text { Lahar } & 0.0 & 35 \\ \mathrm{FI} / 3 & \text { Lavas } & 5.9 & 31 \\ \mathrm{RT} / 1 & \text { Cenizas } & 2.7 & 32 \\ \mathrm{RT} / 2 & \text { Cenizas } & 1.6 & 36 \\ \mathrm{RT} / 4 & \text { Lavas } & 9.8 & 31 \\ \mathrm{SD} / 1 & \text { Tobas } & 6.6 & 38 \\ \mathrm{SD} / 2 & \text { Tobas } & 0.0 & 37 \\ \mathrm{SB} / 3 & \text { Tobas } & 16.0 & 20\end{array}$

Los rangos de variación de los parámetros de resistencia al corte efectivos, medidos por otros autores (Protti, 1993; Chaves \& Avilés, 1993; Bonilla, De Lemos \& Fallas, 1993; Macías \& Zamora, 1993; Tristán, 1994; Fajardo, 1994; Villegas, 1994; Arias, 1995; Alpízar, 1995; Brenes, 1995; Vargas, 1995; Salazar, 1995; Mora, y por el autor de este trabajo, se aprecian en el cuadro 8 y la figura 7 . Se nota que los suelos de orígen volcánico desarrollan, principalmente, resistencia por fricción, y que la resistencia cohesiva es sumamente baja.

La explicación de este comportamiento debe buscarse en la interacción entre las partículas que forman el depósito, es decir en su estructura microscópica y la forma de los granos que lo componen.

Cuadro 8

Rangos de variación de los parámetros de resistencia al corte efectivos de suelos volcánicos

\begin{tabular}{lll}
\hline Litología & $\begin{array}{l}\text { Cohesión } \\
{[\mathrm{kPa}]}\end{array}$ & $\begin{array}{l}\text { ángulo de fricción } \\
\text { interna [grados] }\end{array}$ \\
Brechas & $8.1-9.0$ & $30-31$ \\
Tobas & $0.0-21.9$ & $20-38$ \\
Cenizas & $1.6-16.0$ & $14-38$ \\
Lapilli & 11.0 & 33 \\
Lahar & 0.0 & 35 \\
Lavas & $5.9-9.8$ & 31 \\
\hline
\end{tabular}
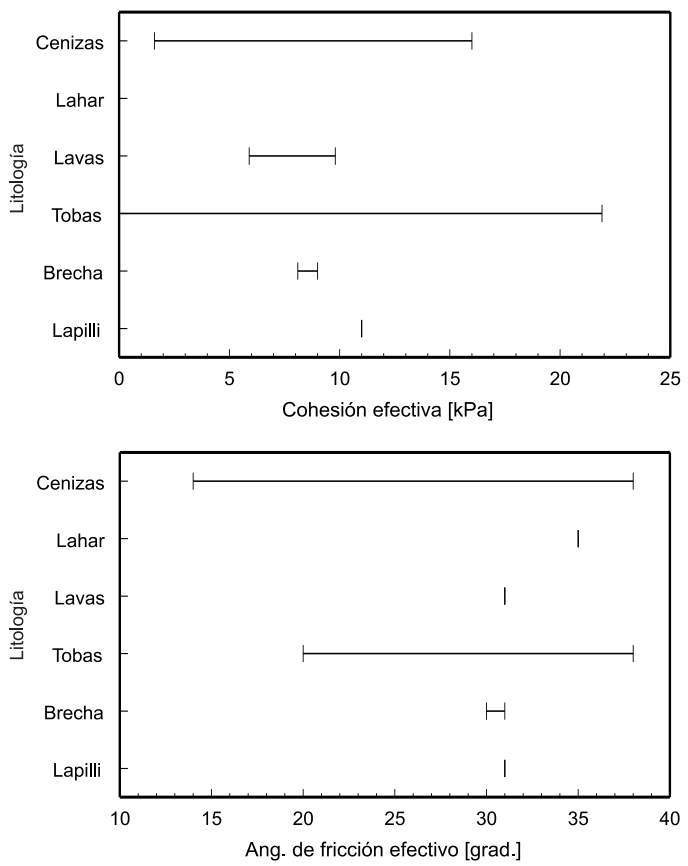

Fig. 7: Rangos de variación de los parámetros de resistencia al corte para los depósitos volcánicos meteorizados. 


\section{MICROFÁBRICAS DE LOS SUELOS VOLCÁNICOS}

Los suelos volcánicos se forman a partir de la meteorización de los productos volcánicos, los cuales son eyectados y transportados de varias maneras: a través del aire con trayectorias balísticas o acarreados por los vientos (tobas, cenizas), derrames de coladas de roca fundida (lavas), avalanchas húmedas de lodo y rocas (lahares).

Microfábrica es un término utilizado para indicar el arreglo de las partículas que componen un suelo y es función de la distribución de los granos dentro del material, su orientación, su empaquetadura y la apertura de fisuras (Selby, 1993). El estudio de las microfábricas de dos suelos volcánicos, producto de la meteorización de tobas y lavas, se ha ejecutado con la toma de micrografías en el microscopio electrónico de barrido (MEB), las cuales se han procesado y analizado con paquetes de dibujo como el CorelDaw 5.0 y FreeHand 5.0.

\section{Microfábrica de tobas meteorizadas}

Las micrografías de la toba meteorizada del sitio Santo Domingo (Figs. 8, 9, 10, 11 y 12) muestran una estructura muy abierta, con una gran cantidad de vacíos separados por agregados de partículas angulares de tamaño limo, en los que se identifica el desarrollo de minerales arcillosos secundarios. El contacto entre las partículas tamaño limo es borde-borde y borde-cara, (Figs. 11 y 12), lo que ha sido interpretado por Selby (1993) como una concentración de valencias insatisfechas en los bordes y esquinas de las partículas. La orientación aleatoria de los contactos entre patículas (Fig. 12) es producto de la depositación de los piroclástos de caída (tobas).

La estructura abierta y la gran cantidad de vacíos justifican los valores altos de porosidad y relación de vacíos, medidos en los materiales de los sitios Santo Domingo y Bolívar (cuadro 1). Los valores de moderados a bajos de la permeabilidad (cuadro 4) se pueden explicar por la tortuosidad de los caminos que debe seguir el agua para moverse a través de este tipo de materiales.

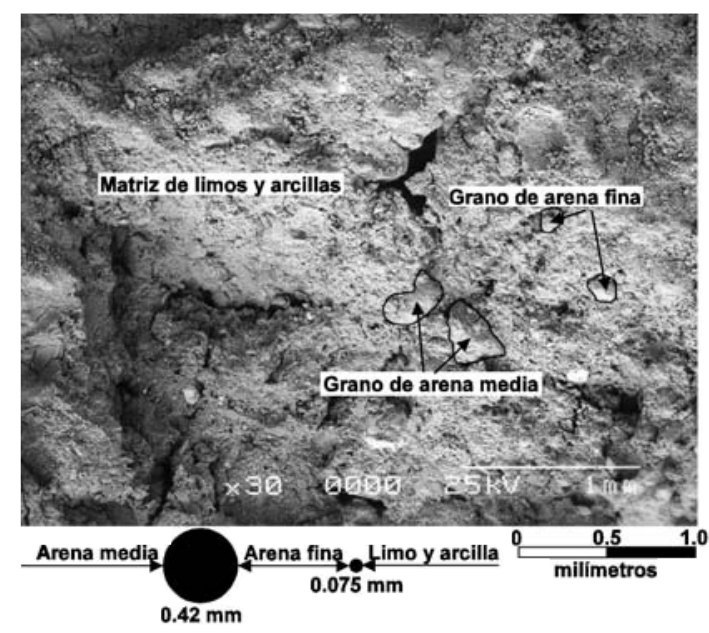

Fig. 8: Microfotografía de una toba meteorizada.

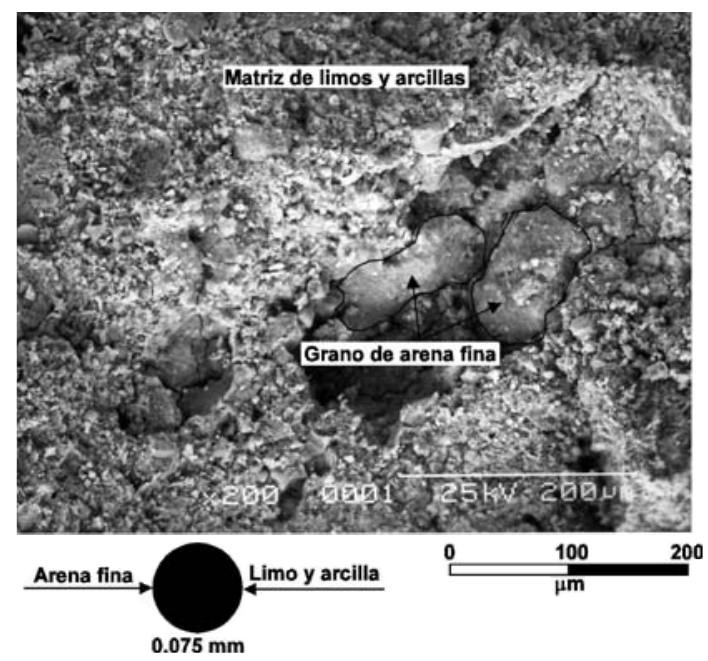

Fig. 9: Microfotografía de una toba meteorizada.

Estas muestras han sido tomadas muy cerca de la superficie del terreno $(<3.5 \mathrm{~m})$, por lo que es de esperarse que con el incremento del espesor del depósito, se produzca una reorientación de las partículas (cara-cara) y una reducción de la relación de vacíos por consolidación, lo cual significaría una disminución de la permeabilidad en función de la profundidad. Lo anterior implica el reconocimiento de que la microfábrica es sumamente importante para el entendimiento del comportamiento de los suelos de origen volcánico.

La presencia de granos de tamaño arena fina (Fig. 9) tapizados por limos y arcillas secundarias, 


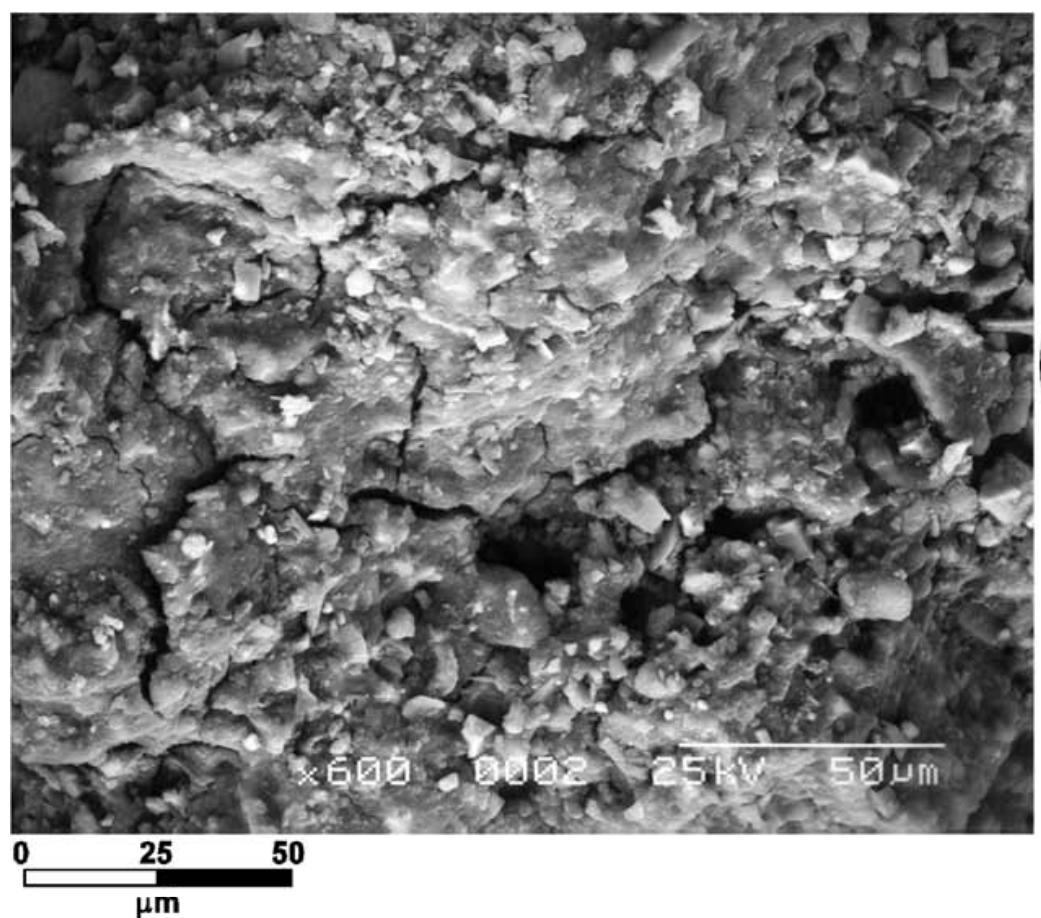

Fig. 10: Microfotografía de una toba meteorizada.

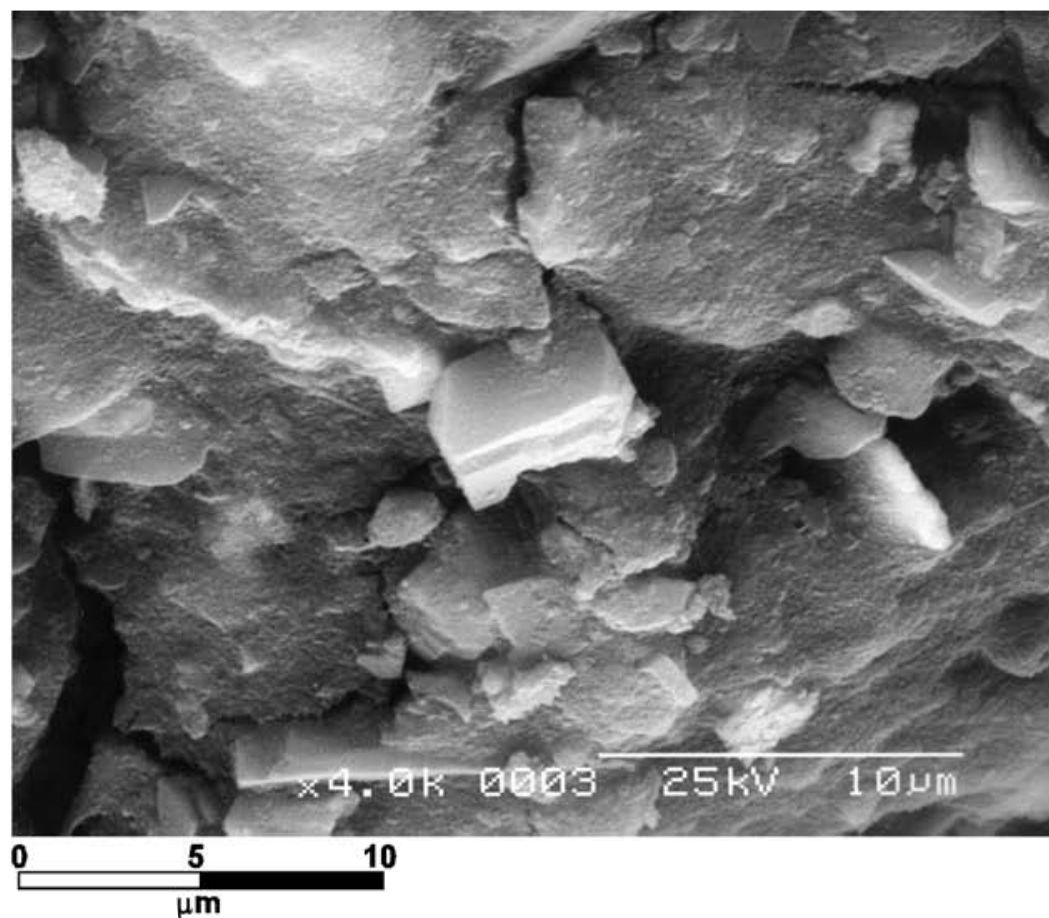

Fig. 11: Microfotografía de una toba meteorizada.
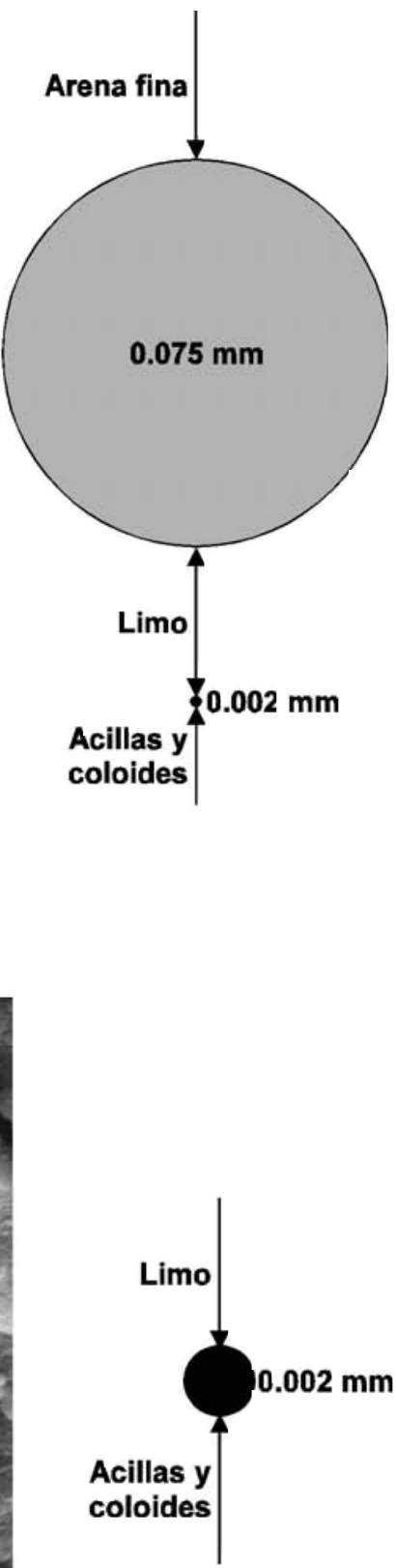


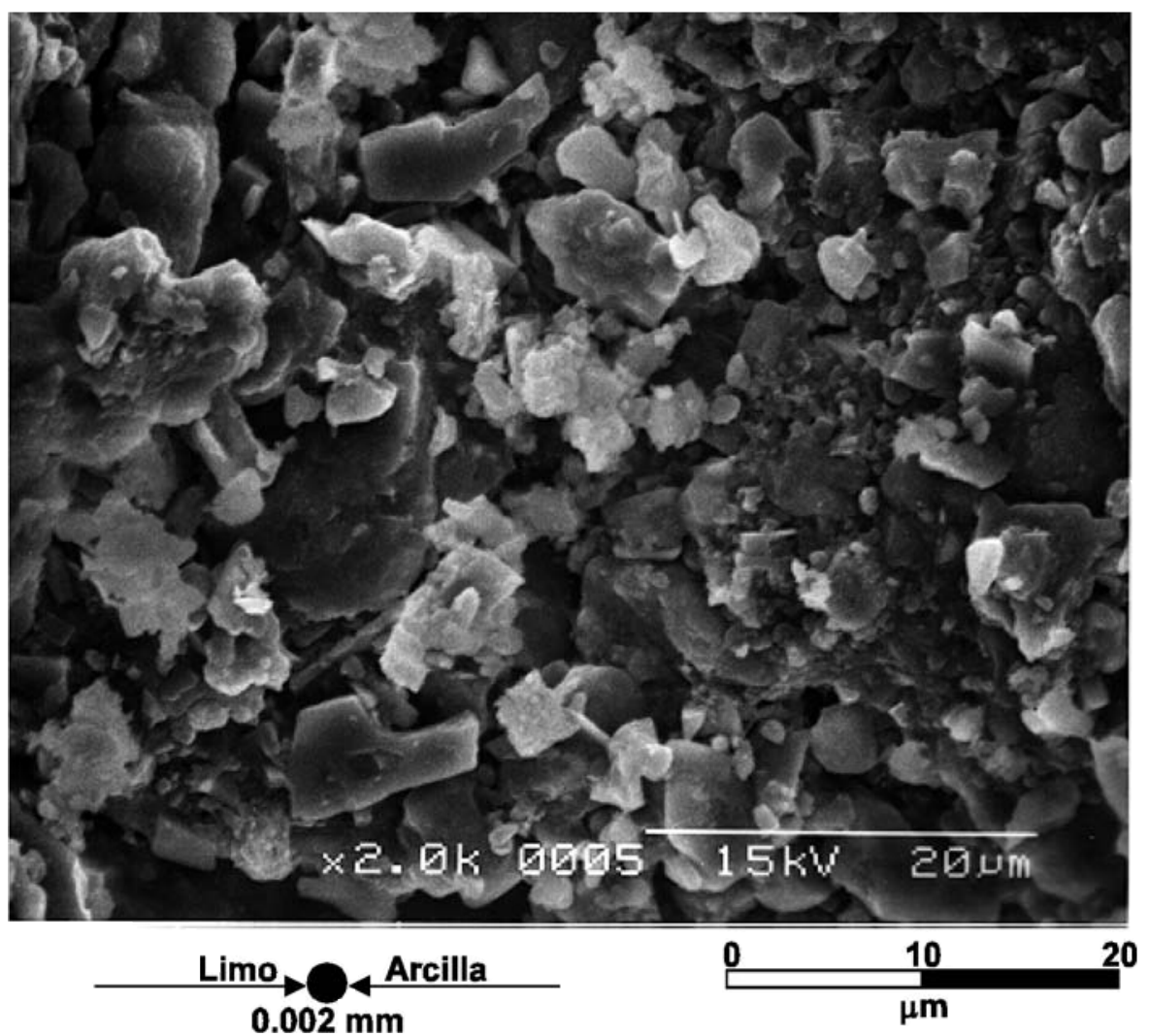

Fig. 12: Aspecto general de la estructura microscópica de una toba meteorizada.

indica que el modelo de fábrica puede considerarse como soportado por matriz. En esta matriz las partículas tamaño limo se encuentran en contacto directo, lo cual explica el desarrollo de la resistencia por fricción en el depósito. La resistencia cohesiva se da por el desarrollo de los minerales secundarios (arcillas, óxidos de hierro), la misma se espera incremente en la medida en que la meteorización del material avanza, lo que a su vez causaría la reducción de la resistencia friccionante. Por lo tanto, esta matriz fina, compuesta principalmente de partículas tamaño limo, es la encargada de regir las propiedades físicas, hidráulicas y mecánicas del material.

\section{Microfábrica de lavas meteorizadas}

Las lavas estudiadas con el microscopio electrónico de barrido (MEB) provienen del sitio Finca Ivancovich y presentan un grado interme- dio de meteorización. Macroscópicamente se observan cristales grandes de plagioclasas y hornblendas, inmersos en una matriz vítrea.

Las micrografías muestran cristales de gran tamaño, fracturados y atacados por la meteorización (Figs. 13 y 14), y una matriz muy meteorizada con fracturas de desecación. La formación de minerales arcillosos secundarios se da por reacción del material de la matriz y por la meteorización de los minerales mediante intercambio iónico (Selby, 1993). El tipo de mineral arcilloso formado depende de los minerales originales de la roca, el clima, el drenaje, la vegetación y el grado de meteorización (Selby, 1993).

En estos materiales volcánicos es de esperarse la formación de arcillas del grupo de la alofana, las cuales se muestran como pequeños cúmulos de forma esferoidal (Fig. 15), que tienden a fracturarse cuando el material se seca, y a expandirse cuando se humedece. 


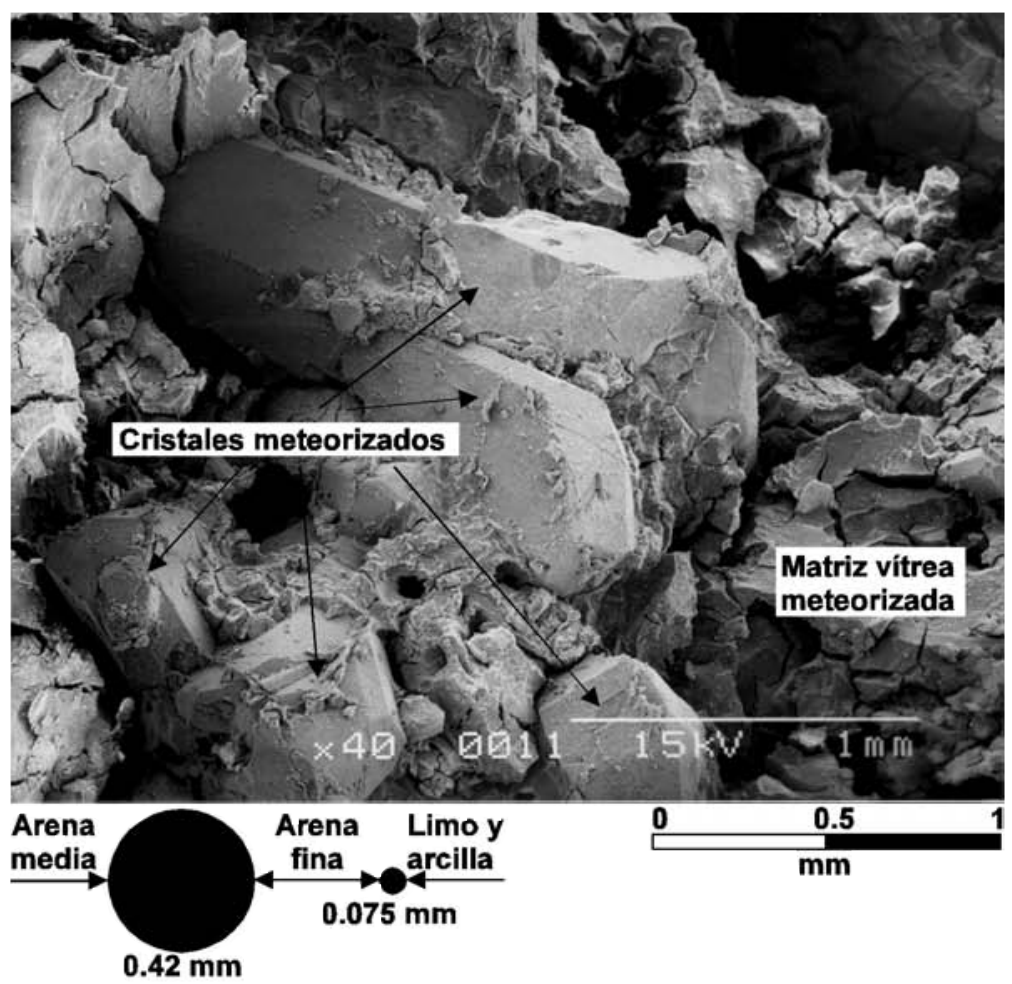

Fig: 13: Microfotografía de una lava meteorizada.

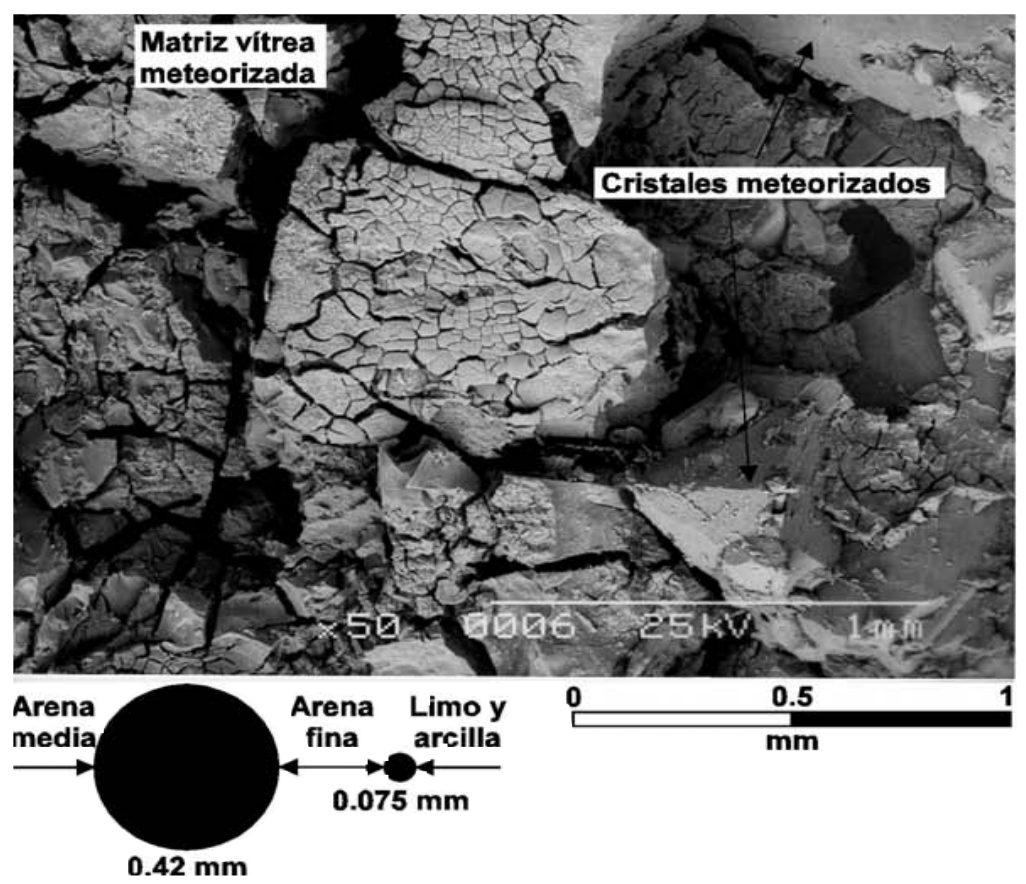

Fig. 14: Microfotografía de una lava meterorizada. 


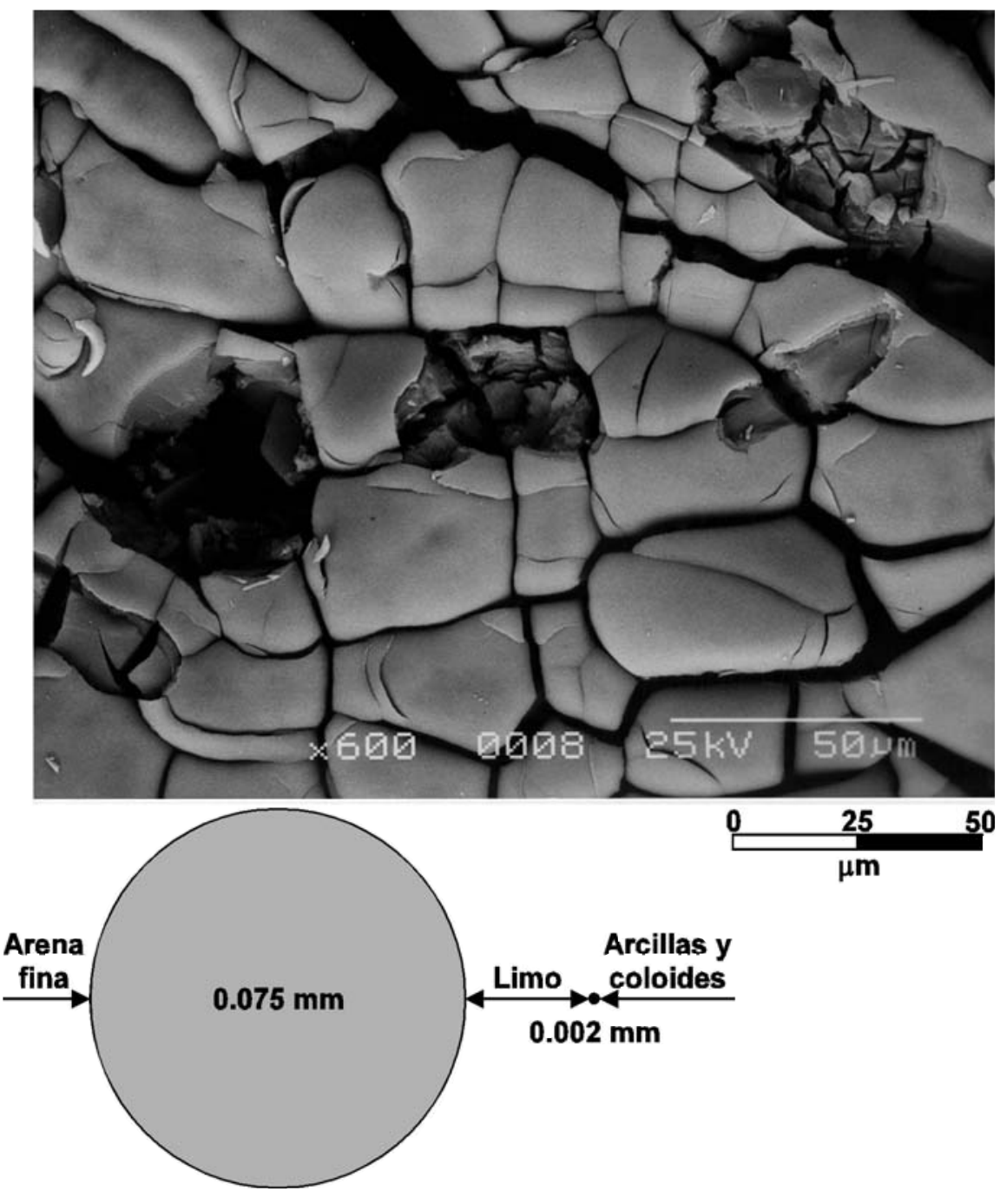

Fig. 15: Microfotografía de una lava meteorizada

\section{CONCLUSIONES}

Los depósitos volcánicos del Valle Central presentan rangos amplios de variación en todas sus propiedades físicas, por causa de los diversos estados de meteorización en que se encuentran, así como por las variedades mineralógicas que se hallan presentes. Lo anterior torna prácticamente imposible discriminar los diversos productos volcánicos de acuerdo con estas propiedades, por lo tanto, para proyectos específicos se hace nece- saria la ejecución de ensayos de campo y laboratorio para su determinación.

Los productos de la meteorización de materiales volcánicos se agrupan, principalmente, en el rango que corresponde con los limos de plasticidad alta $(\mathrm{MH})$, con cierta tendencia hacia los limos de plasticidad muy alta (MV), posiblemente debido al estado más avanzado de meteorización que presentan estos últimos.

Utilizando la ecuasión de Nagaraj \& Jayadeva (1981) con los materiales volcánicos de los 
sitios seleccionados, se obtienen errores que oscilan entre $-11,3 \%$ y $7,2 \%$. Lo anterior significa que la expresión no es adecuada para este tipo de materiales y por lo tanto no puede considerarse como de carácter universal. El error que se obtiene con la expresión desarrollada por el autor, oscila entre $-5,4 \%$ y $4,1 \%$, lo cual la torna un poco más precisa que la de Nagaraj \& Jayadeva (1981), pero sin cumplir plenamente con las expectativas. Apesar de la base científica tan fuerte con que cuentan los métodos de un único punto para la determinación del límite líquido, no se puede realizar una generalización para todo tipo de suelo. Se pueden establecer relaciones empíricas para suelos diversos, en regiones geográficas delimitadas, pero siempre se debe evaluar el error en que se puede incurrir con el uso de las mismas, y así juzgar su posibilidad de aceptación como método alternativo en proyectos de gran envergadura. Para proyectos que no involucren una enorme cantidad de muestras, se sugiere la determinación del límite líquido con el ensayo tradicional del aparato de Casagrande.

Las clasificación de los suelos de origen volcánico se modifica sustancialmente en función del método de ensayo que se utilice, lo cual tiene implicaciones sumamente importantes desde el punto de vista de la aplicación de cada técnica, en el sentido de emplear el Sistema Unificado de Clasificación de Suelos (Bowles, 1982) como un lenguaje universal, con el cual se pueda tener una idea del comportamiento mecánico e hidráulico de cada suelo. Con porcentajes de finos $(<0,074 \mathrm{~mm})$ como los expresados en el cuadro 3 (vía húmeda) para los suelos volcánicos estudiados, podemos esperar que las partículas mayores se encuentren suspendidas en una matriz de suelo fino y establecer que el ensayo vía seca no logra romper las fuerzas interparticulares, conservándose muchos de los agregados y originando resultados que no reflejan la realidad de la distribución granulométrica del depósito.

El rango de variación de la conductividad hidráulica saturada de campo para los productos de la meteorización de materiales volcánicos, es considerablemente amplio (1.0E-04 a 1.0E-07 $\mathrm{m} / \mathrm{s}$ ). Como se pudo establecer los suelos volcánicos, ensayados con el método granulométrico vía seca, se clasifican cmo SM, esto quiere decir que la conductividad hidráulica de los mismos es gobernada por la macroestructura del conjunto de partículas.

Los pesos unitarios secos de los suelos volcánicos analizados oscilan entre 9.8 y 13 $\mathrm{kN} / \mathrm{m} 3$, estos valores se pueden considerar muy bajos y se deben al gran volúmen de vacíos con que cuentan los suelos derivados de la meteorización de productos volcánicos.

La conductividad hidráulica se reduce, prácticamente, en dos órdenes de magnitud con el proceso de compactación, lo cual es sumamente satisfactorio pues se obtiene un material con características impermeables, el cual puede ser utilizado para el revestimiento de trincheras en rellenos sanitarios. Es conveniente, en caso de que se desee utilizar el material en rellenos sanitarios, que se realize un control de la calidad de la compactación estricto, y que además se ejecuten ensayos de permeabilidad en el material compactado, para asegurarse de que se cumplan todas las especificaciones.

Los productos de la meteorización de productos volcánicos cuentan generalmente con cohesiones efectivas muy bajas y con ángulos de fricción efectivos altos

Las micrografías de las tobas meteorizadas del muestran una estructura muy abierta, con una gran cantidad de vacíos separados por agregados de partículas angulares de tamaño limo, en los que se identifica el desarrollo de minerales arcillosos secundarios. La estructura abierta y la gran cantidad de vacíos justifican los valores altos de porosidad y relación de vacíos. Los valores de moderados a bajos de la permeabilidad se pueden explicar por la tortuosidad de los caminos que debe seguir el agua para moverse a través de este tipo de materiales. Es de esperarse que con el incremento del espesor del depósito, se produzca una reorientación de las partículas (caracara) y una reducción de la relación de vacíos por consolidación, lo cual significaría una disminución de la permeabilidad en función de la profundidad. Lo anterior implica el reconocimiento de que la microfábrica es sumamente importante para el entendimiento del comportamiento de los suelos de origen volcánico. La presencia de granos 
de tamaño arena fina tapizados por limos y arcillas secundarias, indica que el modelo de fábrica puede considerarse como soportado por matriz. En esta matriz las partículas tamaño limo se encuentran en contacto directo, lo cual explica el desarrollo de la resistencia por fricción en el depósito. La resistencia cohesiva se da por el desarrollo de los minerales secundarios (arcillas, óxidos de hierro), la misma se espera incremente en la medida en que la meteorización del material avanza, lo que a su vez causaría la reducción de la resistencia friccionante. Por lo tanto, esta matriz fina, compuesta principalmente de partículas tamaño limo, es la encargada de regir las propiedades físicas, hidráulicas y mecánicas del material.

Las micrografías de las lavas meteorizadas muestran cristales de gran tamaño, fracturados y atacados por la meteorización, y una matriz muy meteorizada con fracturas de desecación. En estos materiales es de esperarse la formación de arcillas del grupo de la alofana, las cuales se muestran como pequeños cúmulos de forma esferoidal, que tienden a fracturarse cuando el material se seca, y a expandirse cuando se humedece.

\section{REFERENCIAS}

ALPIZAR, R., 1995: Estudio geológico integral del distrito de San Roque y alrededores, cantón de Grecia, Provincia de Alajuela, Costa Rica. - 70 págs.; Escuela Centroamericana de Geología, Universidad de Costa Rica, Informe Final de Campaña Geológica.

ALVARADO, E., 1994: Estudio Geológico Ambiental y Estratigrafía de la Región Oeste de San Ramón. - 55 págs.; Escuela Centroamericana de Geología. Universidad de Costa Rica, Informe Final de Campaña Geológica.

ARIAS, M. E., 1995: Caracterización geológica de los alrededores de San Juan de Bolívar, distrito 8 del Cantón de Grecia y San Pedro de La Unión, distrito 4 del Cantón de Valverde Vega, Provincia de Alajuela,
Costa Rica. - 103 págs.; Escuela Centroamericana de Geología, Universidad de Costa Rica, Informe Final de Campaña Geológica.

ASTM, 1993: Annual Book of ASTM Standars. Section 4, Construction. Volume 04.08. Soil and Rock; Dimension Stone and Geosynthetics. - 1471 págs.; ASTM, Philadelphia.

BONILLA, J., DE LEMOS, R. \& FALLAS, Y., 1993: Estudio geológico-ambiental de la hoja topográfica Colorado, 3346-III-13, escala 1:10000, Naranjo, Alajuela. - 89 págs.; Escuela Centroamericana de Geología, Universidad de Costa Rica, Informe Final de Campaña Geológica.

BOWLES, J.E., 1982 : Propiedades geofísicas de los suelos. - 490 págs., McGraw-Hill, Bogotá.

BRENES, W., 1995: Estudio geológico integral del sector occidental del cantón de Grecia, Provincia de Alajuela. - 144 págs.; Escuela Centroamericana de Geología, Universidad de Costa Rica; tesis de Licenciatura.

CHAVES, C. \& AVILÉS, L., 1993: Estudio geológico integral de la hoja topográfica Cirrí 3346-III-8 (escala 1:10000), cantón de Naranjo, provincia de Alajuela. - 153 págs.; Escuela Centroamericana de Geología, Universidad de Costa Rica, Informe Final de Campaña Geológica.

DENYER, P. \& ARIAS, O., 1991: Estratigrafía de la Región Central de Costa Rica. - Rev. geoló. América Central, 12: 1-59.

ECHANDI, E., 1981: Unidades volcánicas de la cuenca del río Virilla. - 123 págs.; Escuela Centroamericana de Geología; Universidad de Costa Rica; tesis de Licenciatura.

FAJARDO, H., 1994: Geología de una parte de la hoja Oratorio (1:10 000) cantones Naranjo, 
Palmares y San Ramón, provincia de Alajuela. - 45 págs; Escuela Centroamericana de Geología; Universidad de Costa Rica, Informe final de Campaña Geológica.

KRUSHENSKY, R.D., 1972: Geology of the Istarú Quadrangle, Costa Rica. - Geological Survey Bulletin 1358:1-46.

MACIAS, J. \& ZAMORA, E., 1993: Geología de la hoja topográfica Cañuela. Escala 1.10000, cantón de Naranjo, provincia de Alajuela. - 94 págs.; Escuela Centroamericana de Geología, Universidad de Costa Rica; Informe final de Campaña Geológica.

MORA, M., 1995: Estudio geológico de un sector de sureste de Grecia, Provincia de Alajuela, Costa Rica. - 107 págs.; Escuela Centroamericana de Geología, Universidad de Costa Rica; Informe Final de Campaña Geológica.

NAGARAJ, T.S. \& JAYADEVA, M.S., 1981: Re-examination of one-point methods of liquid limit determination. - Geotechnique, 31,3: 413-425.

PROTTI, R., 1993: Estudio de suelos Café-Teatro Chaklum, Rancho Redondo, San José. - 4 págs.; GEOTEST S.A., Informe inédito.

SALAZAR, J. H., 1995: Estudio geológico ambiental de la hoja topográfica Puente de Piedra 3346III-19 y alrededores (esc. 1:10 000), cantón de Grecia, provincia de Alajuela, Costa Rica. - 97 págs.; Escuela Cen- troamericana de Geología, Universidad de Costa Rica; Informe Final de Campaña Geológica.

SEC, 1986: Guelph Permeameter, 2800KI Operating Instructions. - 28 págs.; Soilmoisture Equipment Corp., Santa Barbara, California.

SELBY, M.J., 1991: Earthís Changing Surface: An Introduction to geomorphology. - 607 págs.; Clarendon Press, Oxford.

TRISTAN, E., 1994: Estudio geológico integral de la sección este de la hoja topográfica San Ramón 3346III-11, esc. 1:10 000, cantón de San Ramón, provincia de Alajuela, Costa Rica. - 129 págs.; Escuela Centroamericana de Geología, Universidad de Costa Rica; Informe Final de Campaña Geológica.

VARGAS, I., 1995: Análisis geológico-ambiental de la zona este-noreste de la ciudad de Grecia, en las hojas, Sarchí y Gertrudis, escala 1:10 000, cantón de Grecia, provincia de Alajuela. - 97 págs.; Escuela Centroamericana de Geología, Universidad de Costa Rica; Informe Final de Campaña Geológica.

VILLEGAS, A. M., 1994: Geología de una parte de la hoja Oratorio 3346III-12, provincia de Alajuela, Costa Rica. - 130 págs.; Escuela Centroamericana de Geología, Universidad de Costa Rica; Informe Final de Campaña Geológica. 